Article

\title{
Human Growth Hormone Delivery with a Microneedle Transdermal System: Preclinical Formulation, Stability, Delivery and PK of Therapeutically Relevant Doses
}

\author{
Mahmoud Ameri, Miryam Kadkhodayan, Joe Nguyen, Joseph A. Bravo, Rebeca Su, \\ Kenneth Chan, Ahmad Samiee and Peter E. Daddona * \\ Zosano Pharma, 34790 Ardentech Court, Fremont, CA 94555, USA; \\ E-Mails: mameri@zosanopharma.com (M.A.); mkadkhodayan@zosanopharma.com (M.K.); \\ jnguyen@zosanopharma.com (J.N.); jbravo@zosanopharma.com (J.A.B.); \\ rsu@zosanopharma.com (R.S.); kchan@zosanopharma.com (K.C.); \\ asamiee@zosanopharma.com (A.S.) \\ * Author to whom correspondence should be addressed; E-Mail: pdaddona@zosanopharma.com; \\ Tel.: +1-510-745-1200; Fax: +1-510-742-6288.
}

Received: 14 February 2014; in revised form: 21 April 2014 / Accepted: 25 April 2014 /

Published: 15 May 2014

\begin{abstract}
This study evaluated the feasibility of coating formulated recombinant human growth hormone $(\mathrm{rhGH})$ on a titanium microneedle transdermal delivery system, Zosano Pharma (ZP)-hGH, and assessed preclinical patch delivery performance. Formulation rheology and surface activity were assessed by viscometry and contact angle measurement. rhGH liquid formulation was coated onto titanium microneedles by dip-coating and drying. The stability of coated rhGH was determined by size exclusion chromatography-high performance liquid chromatography (SEC-HPLC). Preclinical delivery and pharmacokinetic studies were conducted in female hairless guinea pigs (HGP) using rhGH coated microneedle patches at 0.5 and $1 \mathrm{mg}$ doses and compared to Norditropin ${ }^{\circledR}$ a commercially approved rhGH subcutaneous injection. Studies demonstrated successful rhGH formulation development and coating on microneedle arrays. The ZP-hGH patches remained stable at $40{ }^{\circ} \mathrm{C}$ for six months with no significant change in \% aggregates. Pharmacokinetic studies showed that the rhGH-coated microneedle patches, delivered with high efficiency and the doses delivered indicated linearity with average $T_{\max }$ of $30 \mathrm{~min}$. The absolute bioavailability of the microneedle rhGH patches was similar to subcutaneous Norditropin ${ }^{\circledR}$ injections. These results suggest that ZP-transdermal microneedle patch delivery of rhGH is feasible and may offer an effective and patient-friendly alternative to currently marketed rhGH injectables.
\end{abstract}


Keywords: human growth hormone; rhGH; stability; transdermal microneedle patch; pharmacokinetics

\section{Introduction}

There has been a vast growth in the development of biopharmaceutical products over the past two decades and most of these are administered by intravenous or subcutaneous injection. Chronic diseases, such as osteoporosis, diabetes, and growth hormone deficiency, are treated with therapeutic peptides and proteins and for a drug to be of clinical utility it requires years of good patient compliance to attain its therapeutic effect. Thus, a patient-friendly drug delivery system would be desirable alternative for the patient. There is still a paucity of effective methods for administration of therapeutic proteins to patients. Oral delivery is not a viable delivery method for therapeutic proteins due to poor absorption and degradation in the gastrointestinal tract and liver [1,2]. Several alternative routes that avoid first-pass effects and proteolytic degradation include nasal, pulmonary, and transdermal delivery [3]. The nasal route has a limited surface area, also the fast mucociliary clearance, and drainage into the esophagus can result in highly variable absorption [4]. The pulmonary route offers a large and highly vascularized mucosal surface for drug absorption, but the accessibility with currently available inhalers is limited and can additionally be compounded by variability from patient self-administration [5]. The transdermal route offers a large and varied surface as well as ease of application. There are limitations for this type of delivery since molecules with molecular weight greater than $1 \mathrm{kDa}$ are unable to cross the stratum corneum. However, the use of skin permeation enhancers such as DMSO (dimethyl sulfoxide) may be able to transiently decrease the barrier property of the stratum corneum and allow for drug absorption. Permeation enhancer can cause localized irritation as an adverse side effect [6]. To eliminate the use of enhancers, a number of technologies are being developed that utilize physical/mechanical means to traverse the stratum corneum and deliver the drug. The approaches involve ablation of the skin to create aqueous pathways for peptides and proteins. The energy modalities being evaluated include laser [7], radiofrequency [8], heat [9], and sonophoresis [10]. The ablation treatment is followed by transdermal drug patch application over the ablated skin site. Alternatively, transdermal microneedles have been developed as a pretreatment approach prior to application of a transdermal drug patch [11].

Hollow microneedles with aqueous formulation infusion [12,13] and biodegradable drug-incorporated microneedles [14-17] have been developed and tested.

Previous articles $[8,15,16]$ that studied rhGH administration via the microneedle route had non-therapeutic dosages. We describe here a novel drug-coated microneedle patch delivery system that targets high therapeutic doses of rhGH to the epidermal/dermal layer for rapid and efficient delivery. The Zosano Pharma (ZP)-patch system consists of a titanium microneedle array attached to an adhesive patch seated in a retainer ring, and an applicator (Figure 1a). The patch in retainer ring is attached to the bottom of the applicator. The applicator (Figure 1b) is actuated through spring force, which breaks the adhesive from the retainer ring and applies the patch onto the skin site. The drug-coated microneedles physically break the stratum corneum and penetrate the epidermis/dermis, where the dry 
drug coating is dissolved by the surrounding skin interstitial fluid. The ZP-patch system has recently been tested in a Phase 2 clinical study with the delivery of human parathyroid hormone (1-34) peptide for the treatment severe osteoporosis [18].

Figure 1. Transdermal microneedle patch delivery system (a) $5 \mathrm{~cm}^{2}$ adhesive patch with microneedle array $\left(3 \mathrm{~cm}^{2}\right)$ in applicator ring; (b) Zosano Pharma (ZP)-Patch press fit onto the bottom of the applicator; and applicator; (c) 60× magnification of recombinant human growth hormone $(\mathrm{rhGH})$ coated microneedles $\left(580\right.$ microneedles $/ \mathrm{cm}^{2}$, length $340 \mu \mathrm{m}$ and tip angle $60^{\circ}$ ), rhGH coated at $0.5 \mathrm{mg} / 3 \mathrm{~cm}^{2}$ array; and (d) Front view of an individual rhGH coated microneedle $(250 \times$ magnification $)$.

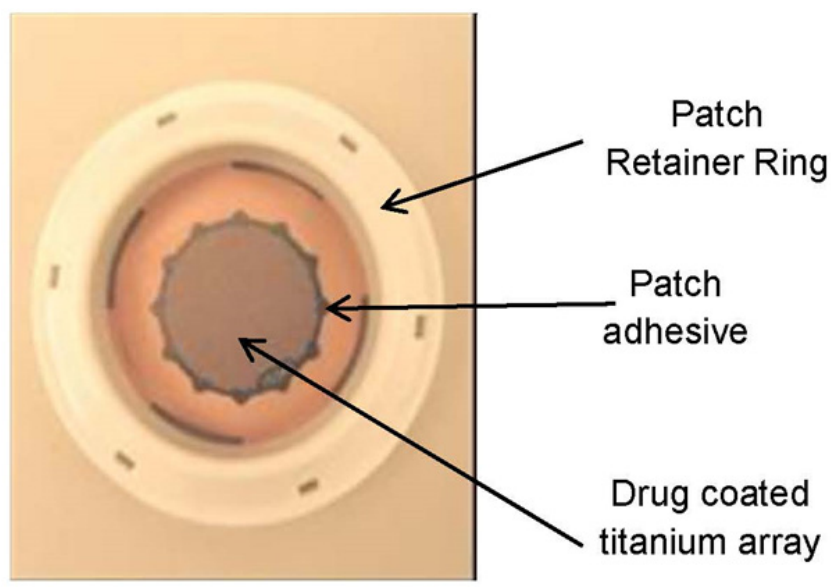

(a) ZP-Drug coated Patch

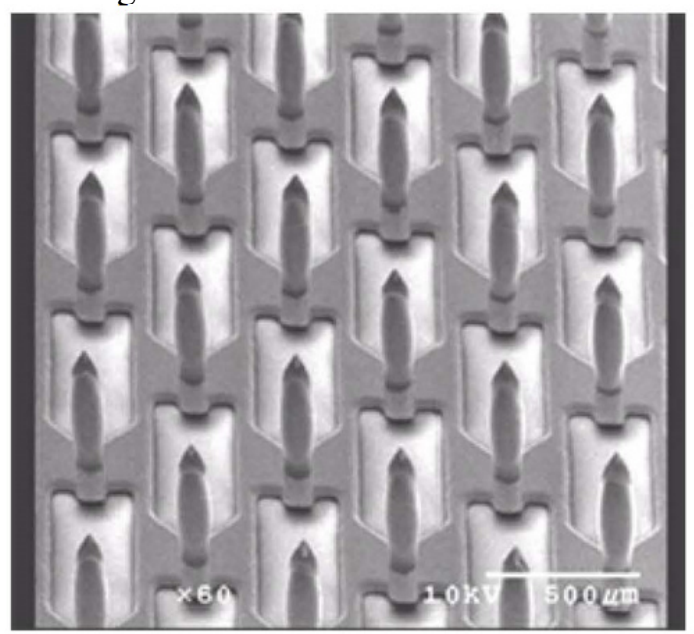

(c) $60 \times$ Magnified section of a rhGH coated microneedles

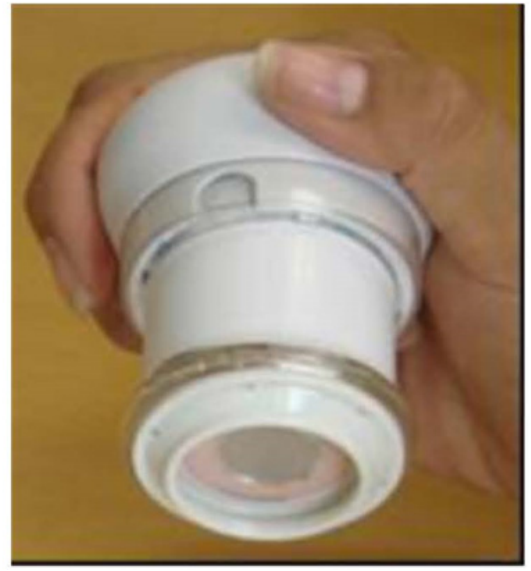

(b) ZP-Patch and applicator

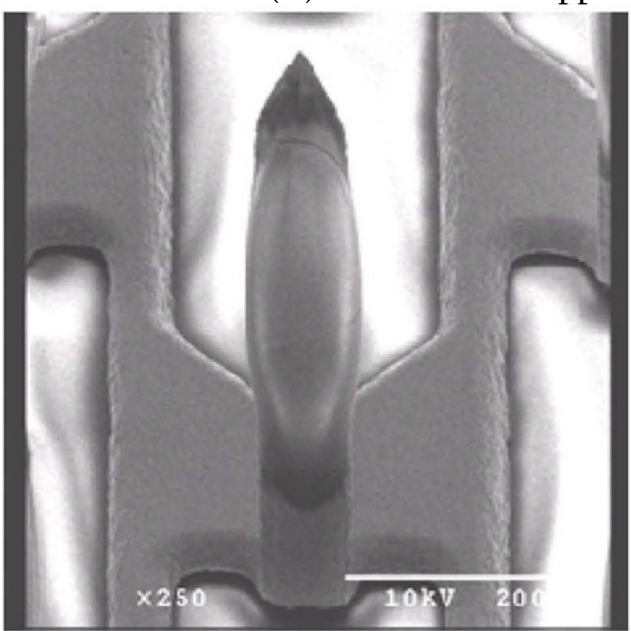

(d) Front view of an individual rhGH coated microneedle $(250 \times$ magnification $)$

\section{Experimental Section}

\subsection{Materials}

Recombinant human growth hormone (rhGH) at a concentration of $13 \mathrm{mg} / \mathrm{mL}$ with $19 \mathrm{mM}$ sodium phosphate buffer, $13.3 \mathrm{mg} / \mathrm{mL}$ glycine and $66 \mathrm{mg} / \mathrm{mL}$ mannitol was purchased from AMEGA Biotech (Buenos Aires, Argentina). rhGH activity was $3 \mathrm{IU} / \mathrm{mg}$. The API (active pharmaceutical ingredient) solution was further processed prior to use as described in the Methods Section. Sucrose NF 
(National Formulary) (high purity, low endotoxin grade) was obtained from Pfanstiehl Laboratories (Waukegan, IL, USA). Polysorbate 20 (Crillet $1 \mathrm{HP}$, high purity, low peroxide) was sourced from Croda (Edison, NJ, USA). Titanium metal sheet (commercially pure grade 2, $25 \mu \mathrm{m}$ in thickness) was obtained from Hamilton Precision Metals (Lancaster, PA, USA).

The ZP-patch system consists of a titanium array of 580 microneedles per $\mathrm{cm}^{2}$. The microneedles are $340 \mu \mathrm{m}$ in length and $70 \mu \mathrm{m}$ in width with tip angle of $60^{\circ}$ (Kemac, Azusa, CA, USA). Other patch components include a polycarbonate ring (Jatco, Union City, CA, USA), adhesive patch (Adhesive Research Inc., Glen Rock, PA, USA), 3 Å molecular sieve desiccant co-molded into the polycarbonate ring (CSP Technologies, Auburn, AL, USA), and an aluminum foil pouch (Mangar, New Britain, PA, USA).

Norditropin $^{\circledR}$ (recombinant human growth hormone; $3.33 \mathrm{mg} / \mathrm{mL}$ ) was produced by Novo Nordisk (Bagsvaerd, Denmark), purchased from a commercial source and stored per the manufacturer's instructions.

\subsection{Methods}

\subsubsection{Diafiltration and Concentration}

Diafiltrated and concentrated rhGH solution was prepared utilizing an Amicon Ultra-15 (Millipore, Billerica, MA, USA) centrifugal filter unit with a $10 \mathrm{kDa}$ molecular weight cut off regenerated cellulose membrane. Approximately $15 \mathrm{~mL}$ of the rhGH solution was placed in the filter unit and centrifuged with a Beckman centrifuge model GS-15R (Beckman, Palo Alto, CA, USA) at RCF $2700 g$ for $30 \mathrm{~min}$. The solution was maintained at $4{ }^{\circ} \mathrm{C}$ during the centrifugation process. Following diafiltration the volume of the protein solution was reduced to a third of the original volume. Recovery of the rhGH concentrate from the Amicon Ultra-15 centrifugal filter units was high, typically $>90 \%$ as determined UV spectroscopy. Sucrose was subsequently added to the concentrated rhGH solution at 1:1 ratio and then lyophilized.

\subsubsection{Lyophilization}

Freeze drying was performed using a LyoStar II lyophilizer (FTS Systems, Stone Ridge, NY, USA) using the following cycle: freezing at $-40{ }^{\circ} \mathrm{C}$ for two hours; primary drying for two hours under the vacuum of $350 \mathrm{mTorr}$ at each temperature of $-40,-30,-20,-10$, and $0{ }^{\circ} \mathrm{C}$; secondary drying at $10{ }^{\circ} \mathrm{C} / 350 \mathrm{mTorr}$ for $2 \mathrm{~h}, 20^{\circ} \mathrm{C} / 350 \mathrm{mTorr}$ for $2 \mathrm{~h}, 30^{\circ} \mathrm{C} / 350 \mathrm{mTorr}$ for $1 \mathrm{~h}, 30^{\circ} \mathrm{C} / 50 \mathrm{mTorr}$ for $0.5 \mathrm{~h}$, and $30{ }^{\circ} \mathrm{C} / 0 \mathrm{mTorr}$ for $0.5 \mathrm{~h}$. Temperature was ramped up at $5{ }^{\circ} \mathrm{C} / \mathrm{min}$ consistently.

\subsubsection{Size Exclusion Chromatography (SEC)}

Soluble aggregates of rhGH were determined by the SEC-HPLC method at wavelength of $214 \mathrm{~nm}$. Chromatography for the assay was performed using a Tosoh Bioscience TSKgel Super SW2000 column (4.6 mm ID $\times 300 \mathrm{~mm}, 5 \mu \mathrm{m})$ (Tosoh Bioscience, King of Prussia, PA, USA) with an isocratic mobile phase (97\% phosphate buffer at $\mathrm{pH} 7.0$ and 3\% iso-propanol) at a flow rate of $0.2 \mathrm{~mL} / \mathrm{min}$, on an HPLC system (Water Alliance 2695, Waters Corporation, Milford, MA, USA) equipped with a binary pump, a thermostatted autosampler and column compartment, and a photodiode array detector (PDA). Data were collected and analyzed using Empower Pro (Empower 2 software, Waters Corporation). 


\subsubsection{Recombinant Human Growth Hormone (rhGH) Purity Determination}

Purity of hGH was determined by the reverse phase (RP)-HPLC method at wavelength of $220 \mathrm{~nm}$. Chromatography for the assay was performed using an Agilent Zorbax 300SB-C8 column $(4.6 \mathrm{~mm}$ ID $\times 150 \mathrm{~mm}, 3.5 \mu \mathrm{m})$ (Agilent, Santa Clara, CA, USA) with an isocratic mobile phase (71\% Tris buffer at $\mathrm{pH} 7.5 ; 29 \% \mathrm{n}$-propanol) at a flow rate of $0.5 \mathrm{~mL} / \mathrm{min}$, on an HPLC system (Water Alliance 2695) equipped with a binary pump, a thermostatted autosampler and column compartment, and a PDA detector. Data were collected and analyzed using Empower Pro (Empower 2 software, Waters Corporation).

\subsection{5. rhGH Content Quantification}

rhGH content was determined by the RP-HPLC method at wavelength of $220 \mathrm{~nm}$. Chromatography for the assay was performed using a Agilent Zorbax 300SB-C8 column ( $4.6 \mathrm{~mm} \mathrm{ID} \times 50 \mathrm{~mm}, 3.5 \mu \mathrm{m})$ with an gradient mobile phase (45\% of $0.1 \%$ trifluoroacetic acid (TFA) in water and $55 \%$ of $0.09 \%$ TFA in acetonitrile from 0 to $2 \mathrm{~min}$, and a wash from 2 to $3 \mathrm{~min}$ ) at a flow rate of $1.0 \mathrm{~mL} / \mathrm{min}$, on an HPLC system (Water Alliance 2695) equipped with a binary pump, a thermostatted autosampler and column compartment, and a PDA detector. Data were collected and analyzed using Empower Pro (Empower 2 software, Waters Corporation). Quantitation was done based on a four-point standard curve (typically 500, 750, 1000 and $1500 \mu \mathrm{g} / \mathrm{mL}$ ) prepared from rhGH USP (United States Pharmacopeia) reference standard (Rockville, MD, USA) in Tris buffer at $\mathrm{pH}$ 7.5.

\subsubsection{Rheology}

Rheological characterization of the liquid formulations was conducted utilizing a rheometer (model CVOR150, Bohlin Instrument, Cranbury, NJ, USA) configured with a cone and plate geometry (a cone angle of $1^{\circ}$ and radius $10 \mathrm{~mm}$ ). Seventy microliters of the liquid formulation was utilized for each experiment.

\subsubsection{Scanning Electron Microscopy (SEM)}

Scanning electron microscopy (SEM) using a Hitachi scanning electron microscope (Model S-2460N) (Hitachi, Tokyo, Japan) was used to view the coating on the microneedles.

\subsubsection{Contact Angle Measurement}

Static contact angle of drug solution formulations on titanium surface was determined using a Future Digital Scientific contact angle meter Model OCA15 (Garden City, NY, USA) employing the "Sessile drop" optical contact angle method. For static contact angle measurement, a photo snapshot was taken once a drop of the solution $(5 \mu \mathrm{L})$ is dispensed from the syringe and laid on a clean titanium foil surface. The angle between the baseline of the drop and the tangent at the drop boundary is measured on both sides. Complete measurement was obtained by averaging the two numbers. A minimum of five readings were recorded for each sample. 


\subsubsection{Microneedle Array Coating and Packaging}

Titanium microneedle arrays were fabricated by a photo/chemical etching and formed using a controlled manufacturing process [19]. Drug formulation $(20 \% w / w \mathrm{rhGH}, 20 \% \mathrm{w} / \mathrm{w}$ sucrose and $0.2 \% \mathrm{w} / \mathrm{w}$ polysorbate 20 ) coating on the microneedle array was conducted at ambient temperature utilizing a roller drum, rotating at $50 \mathrm{rpm}$, in a drug formulation reservoir ( $2 \mathrm{~mL}$ in volume) to produce a drug formulation film of controlled thickness [20]. Microneedle tips on the array are dipped into the thin film and the coating per area controlled by the number of dips (passes) through the drug film. The time between each dip coating was less than $5 \mathrm{~s}$, which was sufficient to dry the formulation coating.

The rhGH-coated microneedle array was assembled with adhesive and retainer ring (Figure 1a). The patch in retainer ring was packaged in an aluminum pouch (Mangar, New Britain, PA, USA) purged with dry nitrogen and heat-sealed with a Multivac heat sealer (model C400) (Multivac, Kansas City, MO, USA).

\subsubsection{Stability Experiments on Packaged Drug-Coated Microneedle Delivery Systems}

The ZP-hGH patch in the sealed pouch was stored in a stability chamber (Model 6010, Caron, Marietta, $\mathrm{OH}, \mathrm{USA}$ ) controlled at $40{ }^{\circ} \mathrm{C} / 60 \% \mathrm{RH}$ (relative humidity). At each time point, three pouch samples were pulled from the stability chamber for HPLC analysis. To extract rhGH from the coated array, the array was first separated from the adhesive by exposing to liquid nitrogen vapor and then peeled from the adhesive. The coated array was then placed in a vial containing $0.5 \mathrm{~mL}$ of sodium phosphate buffer ( $\mathrm{pH}$ 7.4) and mixed for a period of $5 \mathrm{~min}$, of which $250 \mu \mathrm{L}$ of the resulting solution was transferred into a secondary vial for SEC and RP-HPLC analysis.

\subsection{Preclinical Pharmacokinetic Studies}

\subsubsection{Animal Model and Delivery Preparation}

Female hairless guinea pigs (HGP) (body weights $0.4-0.5 \mathrm{~kg}$ ) were obtained from Charles River Laboratories (Wilmington, MA, USA). All animal studies adhered to the NIH Principles of Laboratory Animal Care [21] and were in compliance with the animal welfare regulations in 9 CFR 1-3, the

National Research Council Guide for the Care and Use of Laboratory Animals 1996 [22] and an approved institutional animal care and use committee protocol.

HGPs were anesthetized by intramuscular injection of xylazine $(8 \mathrm{mg} / \mathrm{kg})$ and ketamine $\mathrm{HCl}$ (44 mg/kg). To minimize the stress of anesthesia, the animals were kept warm on a circulating water pad at $37{ }^{\circ} \mathrm{C}$ and carefully monitored. Anesthetized HGPs were catheterized in the carotid artery. The catheter was flushed with saline. Animals were maintained under anesthesia throughout the experiment via injection of sodium pentobarbital $(32 \mathrm{mg} / \mathrm{mL})$ directly into the catheter (0.1 mL/injection).

2.3.2. Zosano Pharma (ZP)-hGH Patch Application, Sub-Cutaneous (SC) and Intravenous (IV) Dosing

ZP-hGH patches were applied to the lateral thorax of HGP $(N=5)$ using a hand held re-usable applicator (total energy $=0.29 \mathrm{~J}$ ). The patch was attached to the applicator and the applicator was 
pressed on the skin, releasing the patch and applying it with a predetermined force using a previously described method [23]. ZP-hGH patches were applied and worn for $1 \mathrm{~h}$ then removed. The ZP-hGH patch doses tested were; 0.5 and $1 \mathrm{mg}$. For the $1 \mathrm{mg}$ dose, two $0.5 \mathrm{mg}$ patches were applied.

Norditropin ${ }^{\circledR}$ SC injections of $0.4,0.8$ and $1.4 \mathrm{mg}$ were used as comparators. Injections were made on the lateral thorax consistent with the patch application sites.

ZP-hGH patch delivery efficiency was assessed by residual drug analysis. The amount of rhGH left on the microneedle array and skin surface after each application were compared against the original coated amount on the microneedle array.

Intravenous dosing of rhGH was used to evaluate the absolute bioavailability of Sub-Cutaneous (SC) injections and rhGH coated patches. The left or right jugular vein of the anesthetized HGP was catheterized (after carotid catheterization). $\mathrm{rhGH}$ injectate was formulated at $205 \mu \mathrm{g} / \mathrm{mL}$ in saline and administered at a dose of $105 \mu \mathrm{g} / \mathrm{kg}$ body weight via direct injection through the jugular catheter. A $0.1 \mathrm{~mL}$ dead volume of the catheter was accounted for in the dosing. The rhGH injectate administered intravenously to all animals were $\leq 0.25 \mathrm{~mL}$ and based on a dose volume $0.5 \mathrm{~mL} / \mathrm{kg}$ body weight.

Local skin tolerability of the ZP-hGH patch was evaluated using the Draize scoring system [24]. Skin site evaluations were made immediately following patch removal.

\subsubsection{Pharmacokinetic Studies (PK)}

Pharmacokinetic samples were collected at $0,5,15,30,60,120,180$, and 240 min to evaluate systemic absorption of rhGH. At each time point, a $0.2 \mathrm{~mL}$ blood sample was collected from carotid artery. Whole blood samples were centrifuged (4000 rpm, $\left.8 \mathrm{~min}, 4^{\circ} \mathrm{C}\right)$, plasma collected and frozen $\left(-80^{\circ} \mathrm{C}\right)$ until assayed. Plasma rhGH was determined by enzyme immunoassay using a human growth hormone Quantikine ELISA kit obtained from the R\&D Systems (Minneapolis, MN, USA). The sensitivity of the assay is $7.2 \mathrm{pg} / \mathrm{mL}$ with a coefficient of variation of $<10 \%$. The rhGH dose delivered by the patch was extrapolated based on the area under the curve (AUC) calculation compared to the SC injection control.

Plasma samples were obtained from alternating groups of animals to minimize the effect of sampling with of 5 animals per time point. Pharmacokinetic parameters were determined by non-compartmental analysis.

\subsubsection{Statistical Analysis}

Results are presented as the mean \pm SE. One way ANOVA was conducted to compare the means $p<0.05$ was considered significant.

\section{Results and Discussion}

\subsection{Formulation Characterization, Microneedle Coating and Stability}

There are two processes, as defined by the coating operation, to produce the drug-coated patch dip coating of microneedles into a high concentration liquid drug formulation, as well as drying and packaging of the solid-state drug formulation, which have been discussed previously [25]. 
Briefly, a liquid formulation is prepared to primarily satisfy three key coating formulation parameters: drug concentration, viscosity, and surface activity.

On this basis a liquid $20 \% w / w \mathrm{rhGH}, 20 \% w / w$ sucrose and $0.2 \% w / w$ polysorbate 20 was prepared. Arriving at this formulation composition was partially driven by chemical stability considerations. The rhGH liquid formulation was formulated to a high concentration $(200 \mathrm{mg} / \mathrm{mL}$; $20 \% \mathrm{w} / \mathrm{w}$ ) to ensure that each dip of microneedles into the liquid formulation can pick up sufficient volume of liquid for drying, which can achieve the desired drug dose with a minimum number of dips. In addition the viscosity of the coating solution, $74 \pm 2 \mathrm{cP}$, was high enough so that the coated liquid will not quickly drip back after dipping but before drying. Sucrose was the primary protein stabilizer and its content was limited to a 1:1 sucrose: $\mathrm{rhGH} w / w$ ratio because increasing sucrose content would add more solid to the coating of the same rhGH dose on the microneedle tips which would eventually blunt the sharpness and hinder skin penetration. A surfactant, polysorbate $20,(0.2 \%)$ was added to the liquid rhGH formulation. This served two purposes firstly as a stabilizer to reduce the formation of insoluble protein aggregates [26] and to decrease the contact angle to $50^{\circ}$ and improve the wetting and coating on the titanium microneedle surface. The rhGH liquid formulation exhibited Newtonian behavior (Figure 2), with the shear stress proportional to the shear rate. This formulation property facilitates a uniform coating of the microneedles as described previously [20].

Figure 2. Shear stress $v$ s. shear rate for $20 \% w / w$ rhGH, $20 \% w / w$ sucrose, $0.2 \% w / w$ polysorbate 20 liquid formulation. Shear stress is proportional to shear rate suggesting Newtonian behavior for the rhGH liquid formulation.

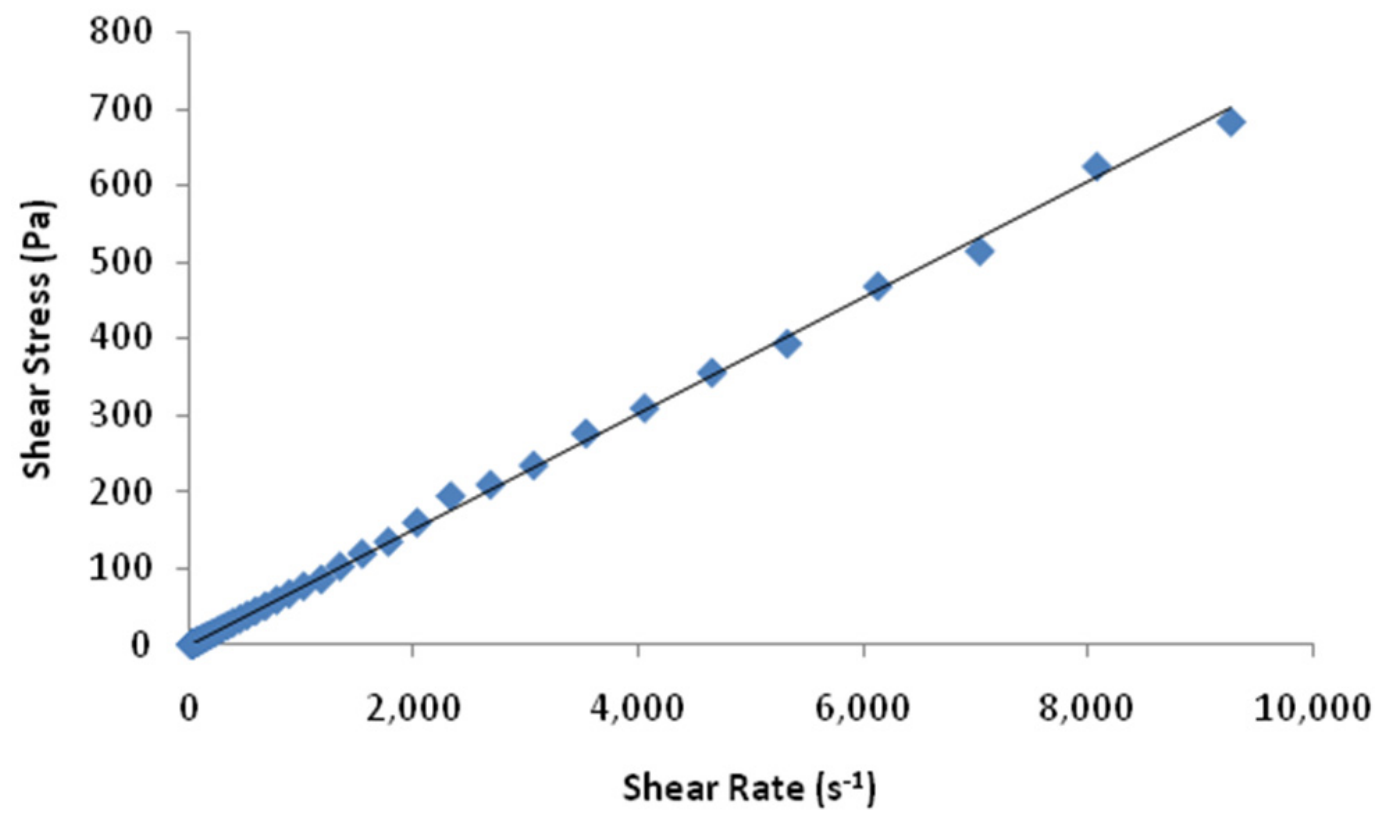

The rhGH liquid formulation was then coated on titanium microneedle array. Figure 1c shows the uniform formulation coating on each of the microneedles within the array as demonstrated by scanning electron microscopy (SEM). The rhGH coating is observed on the microneedle and not on the array structure. The localization of the coating on the microneedle (Figure 1d) is consistent with the thickness of the drug film established by the roller drum. The coating surface is smooth. The rhGH coated amount per square centimeter was $167 \pm 2.4 \mu \mathrm{g}$ and was consistent from batch to batch. 
The assembled ZP-hGH microneedle patches (Figure 1a) were stored at $40{ }^{\circ} \mathrm{C} / 75 \% \mathrm{RH}$. Figure 3 summarizes rhGH monomer (\%) data for $40{ }^{\circ} \mathrm{C} / 75 \% \mathrm{RH}$ up to 6 months. Within the time course of the study ZP-hGH systems held excellent stability; rhGH \% monomer at the 6-month time point is similar to that at $T=0$ and showed no obvious trend of decreasing. The purity of the rhGH coated on the patch was also evaluated and compared with the API. Figure 4 shows that after 6 month storage at $40{ }^{\circ} \mathrm{C} / 75 \% \mathrm{RH}$ there was no difference in the purity of the rhGH coated on the patch relative to the API or rhGH coated patch at $T=0$.

Figure 3. Stability of rhGH-coated microneedle system where the $3 \mathrm{~cm}^{2}$ titanium microneedle array was coated with $0.5 \mathrm{mg}$ dose, assembled on a $5 \mathrm{~cm}^{2}$ adhesive patch within a polycarbonate retainer ring with co-molded desiccant, and heat sealed in a nitrogen-purged foil pouch. The final rhGH-coated microneedle packaged systems were stored at $40{ }^{\circ} \mathrm{C} / 75 \% \mathrm{RH}$ (relative humidity).



Figure 4. Comparison of the purity of rhGH active pharmaceutical ingredient (API) prior to processing and $\mathrm{ZP}-\mathrm{hGH}$ patch after storage at $40{ }^{\circ} \mathrm{C} / 75 \% \mathrm{RH}$ for 6 months.

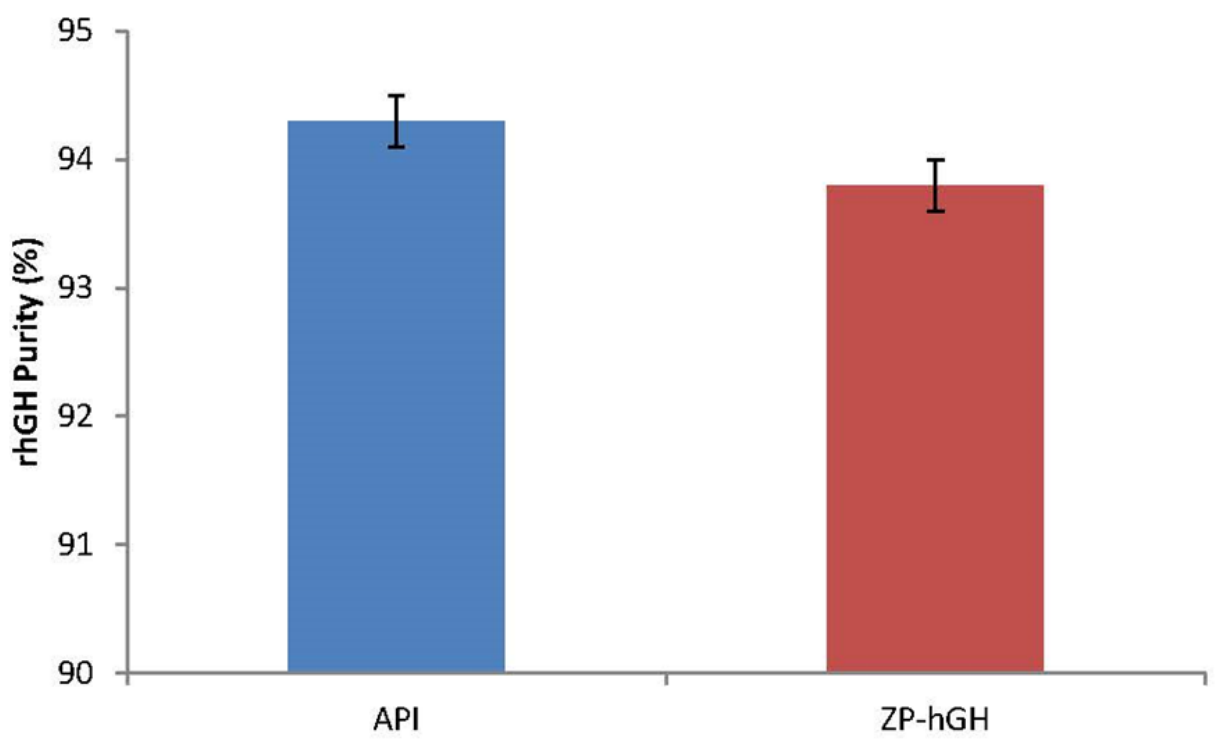




\section{2. rhGH-Coated Microneedle Delivery Performance and Release Kinetics}

rhGH delivery into skin with a patch wear time of $1 \mathrm{~h}$ was: $334 \pm 8$ and $678 \pm 26 \mu \mathrm{g}$ (mean $\pm \mathrm{SE}$ ) for rhGH-coated doses of 0.5 and $1 \mathrm{mg}$, respectively. Delivery efficiency was excellent with $c a$. $70 \%$ of the rhGH-coated dose delivered into the skin (Figure 5a,b).

Figure 5. ZP-hGH delivery performance. (a) delivery into HGP skin; (b) delivery efficiency (\%) with ZP-hGH patch wear time of $1 \mathrm{~h}$. Patches were tested at doses of 0.5 and $1 \mathrm{mg}$.

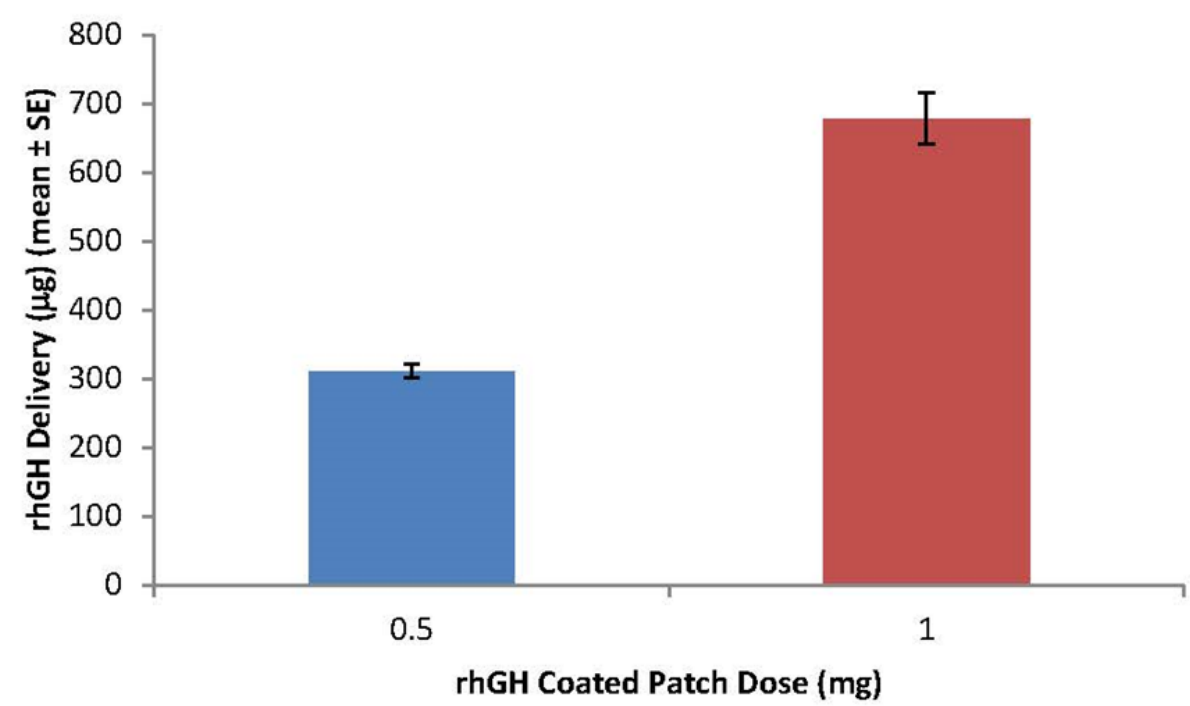

(a)

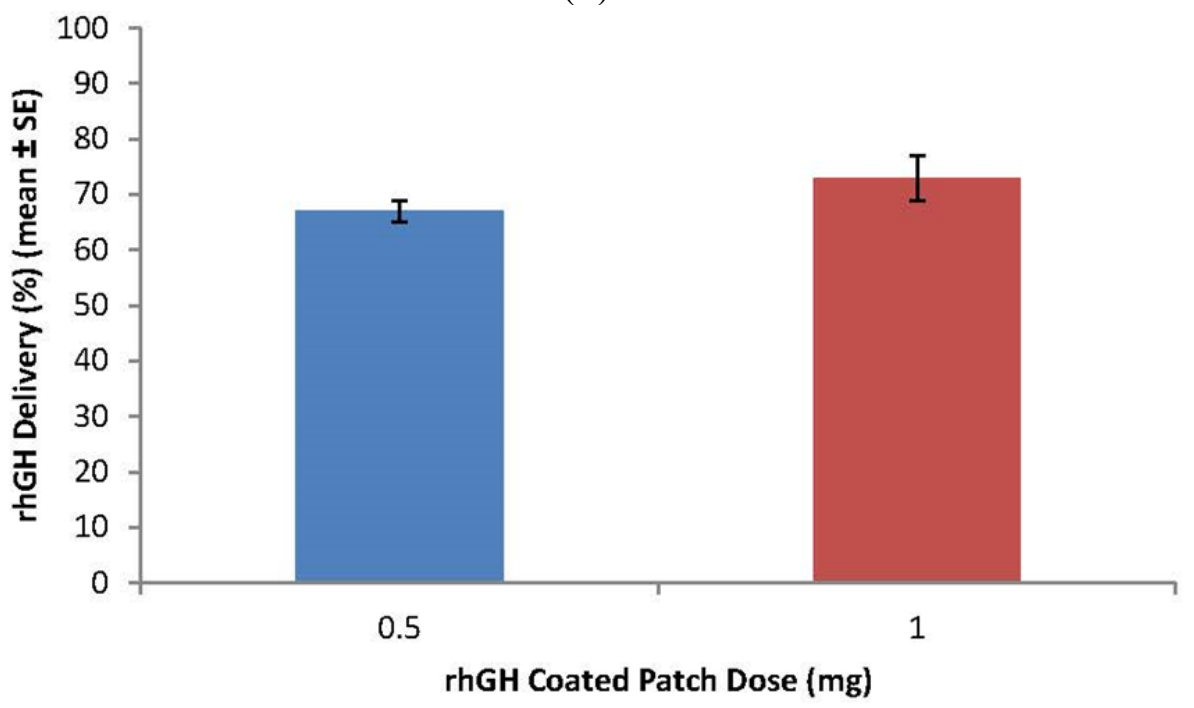

(b)

Local skin tolerability was rated as very good. The erythema scores (maximum possible score: 4) [20] never exceeded 2 and were predominately $0-1$ representing no or barely perceptible erythema. There was no evidence of topical bleeding with any of the treatment conditions. Primary irritation indices (PII) (maximum possible score: 8 ) were 0 to 0.5 and thus categorized as negligible to slight. 


\subsection{Pharmacokinetic Data}

Preclinical in vivo evaluation showed rapid systemic absorption of rhGH with patch administration (Figure 6). There was a linear dose response in terms of both area under the curve $\left(A U C_{t}\right)$ and maximum observed plasma concentration $\left(C_{\max }\right)$ (Figure 7).

Figure 6. Pharmacokinetic (PK) profile of rhGH delivered by microneedle patch or SC injection: ZP-hGH patch $(\diamond 0.5 \mathrm{mg}$ and $\square 1 \mathrm{mg})$; Norditropin ${ }^{\circledR} \mathrm{SC}$ injection $\triangle 0.4 \mathrm{mg}$, $0.8 \mathrm{mg}$ and $* 1.4 \mathrm{mg})$.

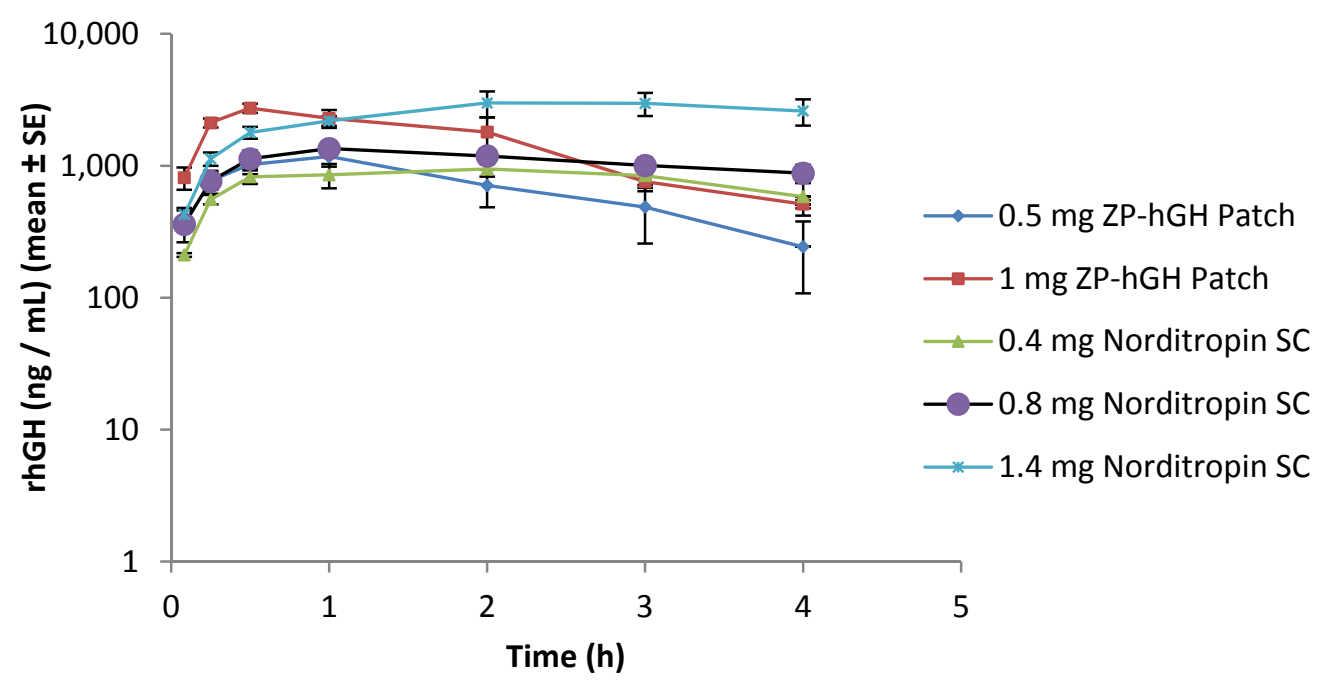

Figure 7. $\mathrm{rhGH}$ plasma concentration of $\mathrm{ZP}-\mathrm{hGH}$ patch at $0.5 \mathrm{mg}$ and $1 \mathrm{mg}$ doses $(\square) v s$. Norditropin ${ }^{\circledR} \mathrm{SC}$ injection over the range of 0.4 to $1.4 \mathrm{mg}(\diamond)$.

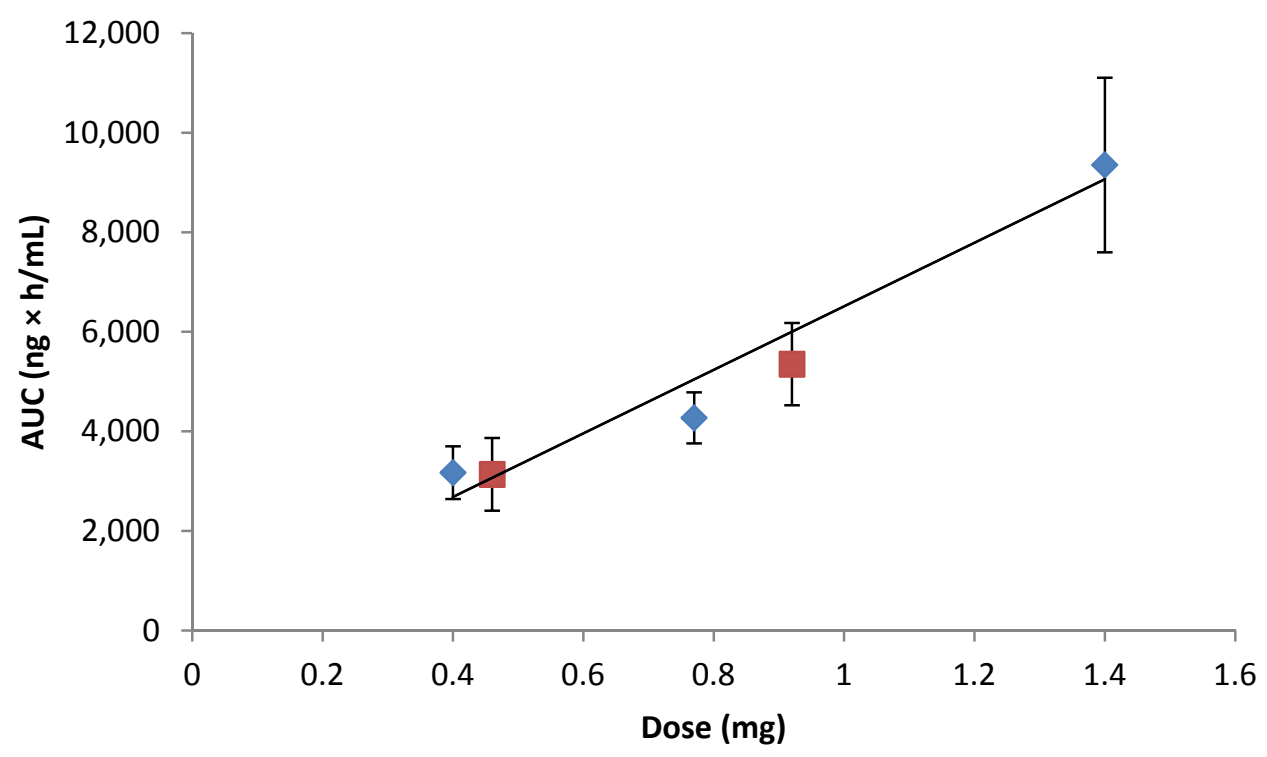

Plasma levels were maintained over $4 \mathrm{~h}$ with $T_{\max }$ at $30 \mathrm{~min}$ and a plasma half-life of $70 \mathrm{~min}$ (Table 1). rhGH patches had an absolute bioavailability of $25 \%$, similar to SC injected Norditropin ${ }^{\circledR}$. The $C_{\max }$ of the $0.5 \mathrm{mg}$ rhGH patch was similar to the $0.8 \mathrm{mg}$ SC injection. The calculated elimination rate constant 
$\left(K_{\mathrm{el}}\right)$ for the patch was $0.5 \mathrm{~h}^{-1}$ compared to $0.15 \mathrm{~h}^{-1}$ for the SC injection. It is not clear from this study whether the administered human doses in this animal model will translate to a faster or equivalent PK profile in the clinic. Other studies suggest that drug-coated microneedle patch delivery can produce a rapid-on and rapid-off PK profile [23,27,28]. This type of delivery may have an advantage over SC administration as growth hormone is secreted in a pulsatile manner in humans [29,30]. In addition, clinical trials suggest that pulsatile growth hormone may be required to increase lipolysis [31,32], while non-pulsatile circulating growth hormone levels may adversely affect insulin sensitivity [33]. However, despite the presumed benefit of pulsatile delivery, recent studies suggest that a long-acting rhGH may be effective in growth-hormone-deficient adults as measured by IGF-1 responses [34]. Nevertheless, a drug-coated microneedle patch still may be an advantageous route of administration for either form of rhGH and provide patients an alternative to needle sticks over the prolonged treatment duration.

Table 1. Comparison of PK parameters for intravenous (IV), ZP-hGH and Norditropin ${ }^{\circledR}$ SC Injection.

\begin{tabular}{ccccccc}
\hline PK parameters & IV & \multicolumn{2}{c}{ ZP-hGH } & \multicolumn{3}{c}{ SC Norditropin } \\
\hline Dose $(\mathrm{mg})$ & 0.05 & 0.5 & 1 & 0.4 & 0.8 & 1.4 \\
$C_{\max }(\mathrm{ng} / \mathrm{mL})$ & $4,766 \pm 421$ & $1,185 \pm 207$ & $2,799 \pm 223$ & $967 \pm 133$ & $1,418 \pm 187$ & $3,193 \pm 613$ \\
$T_{\max }(\mathrm{min})$ & 1 & 30 & 30 & 120 & 60 & 120 \\
$T_{1 / 2}(\mathrm{~min})$ & $25 \pm 2.5$ & $67 \pm 13$ & $73 \pm 12$ & $151 \pm 38$ & $291 \pm 34$ & $362 \pm 19$ \\
$A U C_{t}(\mathrm{ng} \times \mathrm{h} / \mathrm{mL})$ & $1,105 \pm 145$ & $2,774 \pm 730$ & $5,352 \pm 924$ & $3,171 \pm 530$ & $4,270 \pm 513$ & $9,352 \pm 1753$ \\
Absolute & Reference & $27 \pm 6$ & $26 \pm 4$ & $36 \pm 5$ & $24 \pm 2$ & $30 \pm 4$ \\
Bioavailability $(\%) *$ & & & & & & \\
\hline
\end{tabular}

$A U C_{t}(t=0-4 \mathrm{~h}),{ }^{*}$ presented using calculation with dose normalization.

\section{Conclusions}

These studies demonstrate for the first time that a stable, therapeutically relevant rhGH doses can be administered from a microneedle patch with high efficiency and bioavailability.

The rhGH can be formulated at high concentration and coated onto a microneedle patch without generation of soluble aggregates. The rhGH coating formulation at $\sim 200 \mathrm{mg} / \mathrm{mL}$ allowed uniform and localized microneedle coating. ZP-hGH patches stored in sealed nitrogen purged foil pouches with desiccant were stable at $40{ }^{\circ} \mathrm{C}$ storage for at least six months with no significant changes in aggregation and purity.

Preclinical delivery studies in a HGP model showed high drug delivery efficiency for the ZP-hGH patches and a linear dose response at therapeutically relevant SC doses for Norditropin ${ }^{\circledR}$. The bioavailability of the rhGH microneedle patch was similar to the comparable subcutaneous injected Norditropin ${ }^{\circledR}$ dose. These results suggest that transdermal microneedle patch delivery of rhGH is feasible and warrants further development as a patient-friendly alternative to current subcutaneous injection products. 


\section{Author Contributions}

Mahmoud Ameri conducted the main experimental work. Miryam Khadkhodayan measured rhGH in plasma by ELISA. Joe Nguyen, Joseph A Bravo and Ahmad Samiee were responsible for in vivo experiments. Rebeca Su assessed the stability of the ZP-hGH patches by SEC and RPHPLC. Kenneth Chan prepared the formulation and SEM analyses. Peter E Daddona, as the main author, directed and supervised the work.

\section{Conflicts of Interest}

The authors declare no conflict of interest.

\section{References}

1. Singh, R.; Singh, S.; Lillard, J.W., Jr. Past, present and future technologies for oral delivery of therapeutic proteins. J. Pharm. Sci. 2008, 97, 2497-2523.

2. Park, K.; Kwon, I.C.; Park, K. Oral protein delivery: Current status and future prospects. React. Funct. Polym. 2011, 71, 280-287.

3. Florence, A.T.; Attwood, D. Physicochemical Principles of Pharmacy, 3rd ed.; Macmillan Press: London, UK, 1998; pp. 403-447.

4. Cornaz, A.L.; Buri, P. Nasal mucosa as an absorption barrier. Eur. J. Pharm. Biopharm. 1994, 40, 261-270.

5. Wall, D.A. Pulmonary absorption of peptides and proteins. Pharm. Technol. 1995, 2, 1-20.

6. Kligman, A.M. Topical pharmacology and toxicology of dimethylsulfoxide. J. Am. Med. Assoc. 1965, 193, 796-804.

7. Bachhav, Y.G.; Summer, S.; Heinrich, A.; Bragagna, T.; Boehler, C.; Kalia, Y.N. Minimally invasive delivery of peptides and proteins across the skin using P.L.E.A.S.E. ${ }^{\circledR}$ technology. Available online: http://abstracts.aaps.org/SecureView/AAPSJournal/innwg2arlenhmg12c1zw.pdf (accessed on 7 February 2014).

8. Levin, G.; Gershonowitz, A.; Sacks, H.; Stern, M.; Sherman, A.; Rudaev, S.; Zivin, I.; Phillip, M. Transdermal delivery of human growth hormone through RF-microchannels. Pharm. Res. 2005, 22, 550-555.

9. Badkar, A.; Smith, A.; Eppstein, J.; Banga, A. Transdermal delivery of interferon $\alpha-2 B$ using microporation and iontophoresis in hairless rats. Pharm. Res. 2007, 24, 1389-1395.

10. Han, T.; Das, D.B. Permeability enhancement for transdermal delivery of large molecule using low-frequency sonophoresis combined with microneedles. J. Pharm. Sci. 2013, 102, 3614-3622.

11. Badran, M.M.; Kuntsche, J.; Fahr, A. Skin penetration enhancement by a microneedle device (Dermaroller) in vitro: Dependency on needle size and applied formulation. Eur. J. Pharm. Sci. 2009, 36, 511-523.

12. Burton, S.A.; Ng, C.Y.; Simmers, R.; Moeckly, C.; Brandwein, D.; Gilbert, T.; Johnson, N.; Brown, K.; Alston, T.; Prochnow, G.; et al. Rapid intradermal delivery of liquid formulations using a hollow microstructured array. Pharm. Res. 2011, 28, 31-40. 
13. Gupta, J.; Felner, E.I.; Prausnitz, M.R. Rapid pharmacokinetics of intradermal insulin administered using microneedles in type 1 diabetes subjects. Diabetes Technol. Ther. 2011, 13, 451-456.

14. Li, G.; Badkar, A.; Kalluri, H.; Banga, A.K. Microchannels created by sugar and metal microneedles: Characterization by microscopy, macromolecular flux and other techniques. J. Pharm. Sci. 2010, 99, 1931-1941.

15. Fukushima, K.; Ise, A.; Morita, H.; Hasegawa, R.; Ito, Y.; Sugioka, N.; Takada, K. Two-layered dissolving microneedles for percutaneous delivery of peptide/protein drugs in rats. Pharm. Res. 2011, 28, 7-21.

16. Lee, J.W.; Choi, S.O.; Felner, E.I.; Prausnitz, M.R. Dissolving microneedle patch for transdermal delivery of human growth hormone. Small 2011, 18, 531-539.

17. Migalska, K.; Morrow, D.I.; Garland, M.J.; Thakur, R.; Woolfson, A.D.; Donnelly, R.F. Laser-engineered dissolving microneedle arrays for transdermal macromolecular drug delivery. Pharm. Res. 2011, 28, 1919-1930.

18. Cosman, F.; Lane, N.E.; Bolognese, M.; Zanchetta, J.; Garcia-Hernandez, P.A.; Sees, K.; Matriano, J.A.; Gaumer, K.; Daddona, P.E. Effect of transdermal teriparatide administration on bone mineral density in postmenopausal women. J. Clin. Endocrinol. Metab. 2010, 95, 151-158.

19. Cormier, M.; Neukermans, A.P.; Block, B.; Theeuwes, F.T.; Amkraut, A. A Device for Enhancing Transdermal Agent Delivery or Sampling. Eur. Pat. 0914178 B1, 12 March 2003.

20. Ameri, M.; Fan, S.C.; Maa, Y.F. Parathyroid hormone PTH (1-34) formulation that enables uniform coating on a novel transdermal microprojection delivery system. Pharm. Res. 2010, 27, 303-313.

21. National Research Council. Guide for the Care and Use of Laboratory Animals; NIH Publication: Bethesda, MD, USA, 1985.

22. National Research Council. Guide for the Care and Use of Laboratory Animals; National Academy Press: Washington, DC, USA, 1996.

23. Daddona, P.E.; Matriano, J.A.; Mandema, J.; Maa, Y.-F. Parathyroid hormone (1-34)-coated microneedle patch system: Clinical pharmacokinetics and pharmacodynamics for treatment of osteoporosis. Pharm. Res. 2011, 28, 159-165.

24. Draize, J.H.; Woodard, G.; Calvery, H.O. Methods for the study of irritation and toxicity of substances applied topically to the skin and mucous membranes. J. Pharmacol. Exp. Ther. 1944, 82, 377-390.

25. Ameri, M.; Daddona, P.E.; Maa, Y.-F. Demonstrated solid-state stability of parathyroid hormone PTH (1-34) coated on a novel transdermal microneedle delivery system. Pharm. Res. 2009, 26, 2454-2463.

26. Maa, Y.-F.; Nguyen, P.A.; Hsu, S.W. Spray-drying of air-liquid interface sensitive recombinant human growth hormone. J. Pharm. Sci. 1998, 87, 152-159.

27. Cormier, M.; Johnson, B.; Ameri, M.; Nyam, K.; Libiran, L.; Zhang, D.; Daddona, P.E. Transdermal delivery of desmopressin using a coated microneedle array patch system. J. Control. Release 2004, 97, 503-511. 
28. Harvey, A.J.; Kaestner, S.A.; Sutter, D.E.; Harvey, N.G.; Mikszta, J.A.; Pettis, R.J. Microneedle-based intradermal delivery enables rapid lymphatic uptake and distribution of protein drugs. Pharm. Res. 2011, 28, 107-116.

29. Reutens, A.T.; Veldhuis, J.D.; Hoffman, D.M.; Leung, K.C.; Ho, K.K. A highly sensitive growth hormone $(\mathrm{GH})$ enzyme-linked immunosorbent assay uncovers increased contribution of a tonic mode of GH secretion in adults with organic GH deficiency. J. Clin. Endocrinol. Metab. 1996, 81, 1591-1597.

30. Hartman, M.L.; Faria, A.C.; Vance, M.L.; Johnson, M.L.; Thorner, M.O.; Veldhuis, J.D. Temporal structure of in vivo growth hormone secretory events in humans. Am. J. Physiol. 1991, 260, E101-E110.

31. Surya, S.; Horowitz, J.F.; Goldenberg, N.; Sakharova, A.; Harber, M.; Cornford, A.S.; Symons, K.; Barkan, A.L. The pattern of growth hormone delivery to peripheral tissues determines insulin-like growth factor-1 and lipolytic responses in obese subjects. J. Clin. Endocrinol. Metab. 2009, 94, 2828-2834.

32. Cersosimo, E.; Danou, F.; Persson, M.; Miles, J.M. Effects of pulsatile delivery of basal growth hormone on lipolysis in humans. Am. J. Physiol. 1996, 271, E123-E126.

33. Orskov, L.; Schmitz, O.; Jørgensen, J.O.; Arnfred, J.; Abildgaard, N.; Christiansen, J.S.; Alberti, K.G.; Orskov, H. Influence of growth hormone on glucose-induced glucose uptake in normal men as assessed by the hyperglycemic clamp technique. J. Clin. Endocrinol. Metab. 1989, 68, 276-282.

34. Yuen, K.C.J.; Conway, G.S.; Popovic, V.; Merriam, G.R.; Bailey, T.; Hamrahian, A.H.; Biller, B.M.K.; Kipnes, M.; Moore, J.A.; Humpriss, E.; et al. A long acting human growth hormone with delayed clearance (VRS-317): Results of a double blind, placebo controlled, single ascending dose study in growth hormone deficient adults. J. Clin. Endocrinol. Metab. 2013, 98, 2595-2603.

(C) 2014 by the authors; licensee MDPI, Basel, Switzerland. This article is an open access article distributed under the terms and conditions of the Creative Commons Attribution license (http://creativecommons.org/licenses/by/3.0/). 